Esta revista forma parte del acervo de la Biblioteca Jurídica Virtual del Instituto de Investigaciones Jurídicas de la UNAM

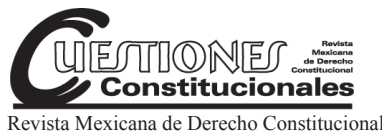

Revista Mexicana de Derecho Constitucional

Núm. 37, julio-diciembre 2017

\title{
CONSTITUCIÓN Y ASPECTOS CONSTITUCIONALES EN TORNO A LA CUESTIÓN DE CUÁNDO ES NECESARIA LA REFORMA CONSTITUCIONAL (UN APUNTE DESDE EL CASO ESPAÑOL)
}

\author{
María Ángeles Ahumada RuIz*
}

1. No podemos saber si la Constitución española se hubiera reformado en más ocasiones y más sustancialmente de haber sido menos exigente el procedimiento de reforma. ${ }^{1}$ Es posible que sí. Es posible también que el

\footnotetext{
* Profesora titular de Derecho constitucional en la Facultad de Derecho de la Universidad Autónoma de Madrid.

1 Desde su aprobación en diciembre de 1978, la Constitución española sólo se ha modificado en dos ocasiones: se adicionaron dos palabras al artículo 13, en 1992, y se aprobó una nueva redacción al artículo 135 en 2011. En ninguno de los dos casos - polémicas aparte - se ha tratado de una reforma estructural. Es exacto, por lo tanto, afirmar que el texto de la Constitución española permanece esencialmente inalterado, que es prácticamente el mismo desde su aprobación. Esto, por supuesto, no implica sostener que la Constitución "no ha cambiado". Aunque el texto siga siendo el mismo, es evidente que la Constitución en 2015 no es la Constitución en 1979, cuando comenzaba su vigencia.

El artículo 168 prevé un procedimiento agravado cuando la reforma propuesta "afecte" al título preliminar (artículos 1o. al 9o.), al capítulo II, sección 1a. del título I (artículos 15-29), al título II ("La Corona", artículos 56-65) o implique la "revisión total" de la Constitución. Desde el primer momento, los estudiosos de la Constitución han advertido no sólo de las dificultades de interpretación de este artículo 168 (¿qué significa "afectar"?), sino también de lo exageradamente costoso de un procedimiento de reforma que, además de las mayorías supercualificadas (2/3 en ambas Cámaras), requiere disolver las Cortes, una convocatoria electoral y un referéndum. El procedimiento "simple" de reforma previsto en el artículo 167 requiere aprobación por 3/5 de cada Cámara y en caso de no lograrse (comisión paritaria por medio), sirve con mayoría absoluta en el Senado y 2/3 en el Congreso. Sólo si 1/10 de los diputados o senadores lo solicita en el plazo de quince días desde su aprobación, la reforma será sometida a referéndum de ratificación.
} 
Esta revista forma parte del acervo de la Biblioteca Jurídica Virtual del Instituto de Investigaciones Jurídicas de la UNAM

constituyente al diseñar el dificultoso procedimiento de reforma pretendiera "obligar" al consenso más amplio para proceder a sustituir o alterar los consensos básicos de la Constitución. ${ }^{2}$ En la práctica, sin embargo, lo que parece es que la vía agravada de reforma - la prevista en el artículo 168 de la Constitución- contiene un mecanismo de "autobloqueo": si los constituyentes agravaron el procedimiento en evidente muestra de desconfianza hacia las mayorías parlamentarias ocasionales, éstas, por su parte, prefieren evitar la reforma, incluso si están de acuerdo en su conveniencia, ante la incertidumbre (de nuevo, desconfianza) que genera un procedimiento que exige el escrutinio popular sucesivo y por partida doble (elecciones generales y posterior referéndum).

2. En todo caso, la llamativa resistencia a la reforma de la Constitución española resulta problemática no porque desincentive reformas drásticas, sino porque desincentiva todo tipo de reforma, también las que pueden considerarse objetivamente convenientes. El "efecto desaliento", en nuestro caso, lo provoca la combinación de dos factores: una regulación de la reforma definitivamente disuasoria (poco clara y enormemente costosa cuando entra en aplicación el artículo 168, CE) y el fuerte valor simbólico de la Constitución de 1978. Este valor simbólico parece primar sobre la visión más instrumental de la Constitución como súper ley, como conjunto normativo fundamental, algo que tiene enormes ventajas en la medida en que refuerza el sentimiento colectivo de apego a la Constitución, pero también grandes inconvenientes, desde el momento en que ésta se idealiza. No obstante, puede muy bien suceder que aunque las dificultades que pone el procedimiento de reforma permanezcan, las que derivan del apego al consenso inicial se reduzcan con el tiempo. Tiene sentido suponer que las nuevas generaciones que siempre han vivido en democracia no se consideren "atadas" por los pactos de la transición del mismo modo que las que vivieron el proceso.

3. ¿Cuándo resulta necesaria la reforma constitucional? Sobre esto no hay un canon establecido. Teóricamente es necesario acudir a la reforma cuando no es posible realizar adaptaciones del derecho constitucional en vigor ni por vía legislativa ni por vía de interpretación. Ya decía Kelsen que toda ley inconstitucional es una ley de reforma de la Constitución que se aprueba por el procedimiento equivocado $\mathrm{y}$, en cuanto a los excesos interpretativos,

2 No todo lo "protegido" por el procedimiento agravado del artículo 168, CE es reflejo de un "consenso básico". De hecho, la selección de las porciones súper-rígidas de la Constitución española plantea una variedad de interrogantes. 
Esta revista forma parte del acervo de la Biblioteca Jurídica Virtual del Instituto de Investigaciones Jurídicas de la UNAM

la categoría "mutación constitucional", se acuña precisamente para calificar los cambios de la Constitución que se producen al margen del procedimiento previsto de reforma.

La práctica de los países de nuestro entorno confirma que las reformas constitucionales obedecen a objetivos muy variados. La importantísima reforma constitucional francesa de 2008 se presentó como "ley constitucional de modernización de las instituciones de la V República"; Alemania recurre a las reformas siempre que hay decisiones fundamentales que afectan al sistema federal (y ha habido muchísimas reformas, más de cincuenta, que no sólo han consistido en cambiar artículos de la Constitución, sino también en añadir otros nuevos); y más curioso y llamativo es el caso del Reino Unido, que pese a no tener una Constitución escrita, tramita como "Constitucional Reform Bills" las regulaciones que afectan a órganos constitucionales (seguramente, la reforma de este tipo más importante en los últimos tiempos es la que ha fundado un Tribunal Supremo definitivamente independizado de la Cámara de los Lores, pero también la que alteró las funciones del lord Chancellor o la que suprimió la mayor parte de los derechos hereditarios sobre los escaños de la Cámara de los Lores).

4. En buena lógica no deberían plantear problemas insuperables las modificaciones constitucionales que se planteen como esencialmente técnicas, de actualización, correctoras de defectos o que suplen carencias. Para lo demás, la reforma de la Constitución es una prueba de resistencia... y hay muchos buenos argumentos para preferir la estabilidad de una Constitución. A la hora de la verdad, incluso si la Constitución no incorpora cláusulas de intangibilidad que declaran irreformables algunas partes o determinaciones de la norma fundamental (normalmente, las relativas a la forma de Estado, o de gobierno, o a los derechos inviolables) — ciertos contenidos de ella son esenciales, porque construyen señas de "identidad constitucional", o se identifican con componentes imprescindibles e irrenunciables de cualquier sistema que aspire a ser reconocido como una democracia constitucionalsu alteración implicaría la ruptura del vínculo con el pacto inicial y, según el caso, el abandono de los principios mismos del constitucionalismo democrático.

5. Una última reflexión para concluir este breve apunte. En buena medida, la discusión sobre la reforma de la Constitución es, de igual forma, la discusión sobre lo que debe estar en la Constitución. Las democracias constitucionales se caracterizan por haber apartado de la contienda política ordinaria algunas cuestiones, que quedan fijadas en la Constitución. 
Esta revista forma parte del acervo de la Biblioteca Jurídica Virtual del Instituto de Investigaciones Jurídicas de la UNAM www.juridicas.unam.mx https://biblio.juridicas.unam.mx/bjv https://revistas.juridicas.unam.mx

DOI: http://dx.doi.org/10.22201/iij.24484881e.2017.37.11462

Pero eso no las aparta "para siempre" de la discusión política. El constitucionalismo es una técnica de gobierno y como todo invento humano está, lamentablemente, lejos de la perfección. La Constitución es una norma ni más ni menos, y, en cuanto tal, carece de propiedades taumatúrgicas: las cuestiones que dividen a la sociedad difícilmente dejarán de hacerlo sólo porque una mayoría, por cualificada que sea, las fije en la Constitución; para que sea respetada debe resultar integradora, facilitar la convivencia y poner las bases para una sociedad mejor y más justa. Pero también debe dejar espacio para la política del día a día. En este sentido, es importante recordar que la Constitución no debe servir para preservar un statu quo que no beneficia a todos por igual y dificulte cambios. En nuestro caso, el gran desafío de nuestra Constitución, con reforma o sin ella, está en que conserve su principal virtud: que siga siendo, a lo largo del tiempo y con el cambio de las generaciones, la Constitución de todos. 